\title{
Effect of geometrical parameters in micro-grooved crosshatch pattern under lubricated sliding friction
}

\section{$\operatorname{AUTHOR}(\mathrm{S}):$}

Suh, Min-soo; Chae, Young-hun; Kim, Seock-sam; Hinoki, Tatsuya; Kohyama, Akira

\section{CITATION:}

Suh, Min-soo ... [et al]. Effect of geometrical parameters in micro-grooved crosshatch pattern under lubricated sliding friction. 2010, 43(8): 1508-1517

\section{ISSUE DATE:}

2010-08

URL:

http://hdl.handle.net/2433/134578

\section{RIGHT:}

(C) 2010 Elsevier Ltd; This is not the published version. Please cite only the published version.; この論文は出版社版でありません。引用の際に は出版社版をご確認ご利用ください。 


\title{
EFFECT OF GEOMETRICAL PARAMETERS IN MICRO- GROOVED CROSSHATCH PATTERN UNDER LUBRICATED SLIDING FRICTION
}

Min-soo Suh ${ }^{\mathrm{a}, *}$, Young-hun Chae ${ }^{\mathrm{b}}$, Seock-sam Kim ${ }^{\mathrm{c}}$ Tatsuya Hinoki $^{\mathrm{d}}$ and Akira Kohyama ${ }^{\mathrm{d}}$

${ }^{a}$ Graduate School of Energy Science, Kyoto University, Gokasho, Uji, 611-0011, Kyoto, Japan

${ }^{b}$ Engineering of Tribology Institute, Kyungpook National University, 1370 Sankyuk-dong, Buk-gu, 702-701, Daegu, Republic of Korea

${ }^{\mathrm{c}}$ Department of Mechanical Engineering, Kyungpook National University, 1370 Sankyuk-dong, Buk-gu, 702-701, Daegu, Republic of Korea

${ }^{\mathrm{d}}$ Institute of Advanced Energy, Kyoto University, Gokasho, Uji, 611-0011, Kyoto, Japan

\begin{abstract}
Tribological test was carried out using a pin-on-disc geometry with fabricated SKD11 pin on bearing steel disc, under sliding in paraffin oil. Fabrication has been made with various angles and widths of crosshatch pattern. The effects of geometrical parameters on friction were mainly examined in mixed and elastohydrodynamic lubrication. The result shows that friction control could achieve by fabricating micro-grooved crosshatch pattern on contact surface. It is observed that each geometrical parameter of texture influence on friction, especially decrease of groove aspect ratio and increases of groove sliding length show friction reduction performance. Crucial parameter $G_{1}$ was proposed for micro-grooved crosshatch texture.
\end{abstract}

KEYWORDS: Surface Texturing; Crosshatch pattern; Groove; Sliding friction; Photolithography

${ }^{*}$ Corresponding author. Tel.: +81 77438 3465; fax: +81 774383467 .

E-mail address: M.S.Suh@gmail.com (M.-S. Suh). 


\section{INTRODUCTION}

Surface texturing, one of the methods to control the friction, is the technology to modify the surface by fabricating texture patterns to control the friction properties of relative motion. In general, friction properties play an important role in most industrial processes in the view point of energy and material dissipation. Future development of this technology requires clear understanding of the basic design guidelines to guide investment decisions in equipment and expertise.

There are many studies and reports that texturing technology improves load carrying capacity, and friction performance of tribological components significantly [1-6]. Theoretical studies also have been reported regarding geometric parameters of textures [710] and it emphasized that these parameters are one of the most important factor to optimize texturing benefits. The known results of "why these features work" can provide marked improvement in terms of friction and wear reduction. And mostly, discovery and optimization of the surface texturing are carried out in the form of Edisonian approach. There are no doubts that surface engineering is the next generation technology most relevant to industrial applications. But due to the complex nature of phenomenon the correlation and understanding of each parameter has not been completely known and only in limited cases had been analytically described. Most of the known mechanisms were about discrete texture concerning a pit area ratio and a shape of pattern [11-17] besides few of work have been done for crosshatch groove surface texture, in the view point of geometric parameter.

There are two general types of textures, a discrete and a continuous texture (see figure 1). Various shape of feature e.g. circle, rectangular, triangle, honeycomb, and etc. are being applied in discrete texture. Continuous texture has an array of straight line or curved line in parallel or crosshatch form. These differences in design of surface textures will change the contact pressure contours inside the contact. The technical challenge is to determine the critical dimensional relationships between the width, length, and depth of the feature, the distance between features (pitch, array, angle for directions), and the edge contour control (see figure 2). Those requirements cost money and vary depending on application and operating conditions of the components. Table 1 shows the major difference of each general texture regarding geometric parameters. 
Table 1 Geometric parameters of each general texture.

Geometric parameters

Type of texture

Width $^{1}$ Length Depth $^{1}$ Pitch $^{2}$ Angle Array

Edge Texture

contour area ratio

\begin{tabular}{lllllllll}
\hline Discrete texture & $\checkmark$ & $\checkmark$ & $\checkmark$ & 0 & $\times$ & 0 & $\checkmark$ & $\checkmark$ \\
Continuous texture & $\checkmark$ & $\checkmark$ & $\checkmark$ & 0 & $x^{3}$ & 0 & $\checkmark$ & $\checkmark$ \\
Crosshatch texture & $\checkmark$ & $\checkmark$ & $\checkmark$ & 0 & $\checkmark^{3}$ & $\times$ & $\checkmark$ & $\checkmark$ \\
\hline
\end{tabular}

$\checkmark$ Important $\quad{ }^{1}$ Aspect ratio of width/depth is an important factor in terms of friction performance

Marginal $\quad{ }^{2}$ Pitch has a dependence character with texture area ratio

$\times$ Unfavourable $\quad{ }^{3}$ Angle parameter is known for crosshatched groove only

Discovery of the crucial design parameters and the correlation of geometrical parameters are necessary to get the maximum benefits so that it can improve the performance and pursue engineering applications of such concepts in gears, cams, bearings, and wear interfaces. In this study, the micro-grooved crosshatch pattern for sliding under lubrication was studied, and the correlation of crosshatch angle and width for friction under regime of mixed and elastohydrodynamic lubrication were examined.

\section{MATERIAL AND EXPERIMENTAL PROCEDURE}

\subsection{Material}

In the present study, the tribological behaviour of two steel pair material tool steel (SKD11, JIS) and the bearing steel was tested under sliding in paraffin oil with a pin-on-disc geometry. Before surface texturing, the upper pin specimens were ground and polished to a mirror finish with $3 \mu \mathrm{m}$ diamond paste. The final surface roughness $\mathrm{R}_{\mathrm{a}}$ before texturing was $0.05-0.10 \mu \mathrm{m}$.

Table 2 shows the geometrical parameters of specimens. Crosshatch angle varies in the range from $60^{\circ}$ to $20^{\circ}$ and width are from $100 \mu \mathrm{m}$ to $40 \mu \mathrm{m}$. Groove area ratio is an ratio of textured over untextured, in this study it is equally set to $20 \%$. 
Table 2 Geometrical parameters of test specimens.

\begin{tabular}{lcc}
\hline $\begin{array}{l}\text { Parameter of crosshatched } \\
\text { groove texture }\end{array}$ & Value & Step \\
\hline Angle, $\theta_{R}$ [degree] & $20,30,40,50,60$ & 5 \\
Area ratio $[\%]$ & 20 & 1 \\
Depth, $\mathrm{d}[\mu \mathrm{m}]$ & $5 \pm 0.5$ & 3 \\
Width, $\mathrm{w}[\mu \mathrm{m}]$ & $40,70,100$ \\
Aspect ratio, $\mathrm{G}_{\mathrm{r}}{ }^{*}$ & $0.125,0.07,0.05$ & 3 \\
\hline
\end{tabular}

* $\mathrm{G}_{\mathrm{r}}$ is an aspect ratio of groove depth over groove width (groove depth is considered fix as $5 \mu \mathrm{m}$ )

\subsection{Surface microtexturing}

Photolithography microtexturing, a process used in micro-fabrication to selectively remove parts of the bulk of a substrate, on polished surface was carried out on upper-pin specimens of SKD1 1 steel. It was employed because it affords exact control over the shape and size of the texture it creates, and can create patterns over an entire surface simultaneously. UV (ultraviolet) light was used to transfer a geometric pattern from a photomask to photoresist, a light-sensitive chemical, on the substrate. This process, as shown in figure 3, combines several steps in sequence; coating, exposure and developing, etching, and baking. Spin coater (PR: AZ-1512) device was used for coat Novolac resin as positive photo resistant via 3 steps, each step runs at different rpm and holding time $(2500 \mathrm{rpm} / 5 \mathrm{sec}, 3500 \mathrm{rpm} / 25 \mathrm{sec}$, and $2500 \mathrm{rpm} / 5 \mathrm{sec}$ ) and produces a layer between 2.0 and $2.5 \mu \mathrm{m}$ thick. The spincoating process results in an amazingly uniform thin layer, usually with uniformity within 5 to 10 $\mathrm{nm}$. The photoresist is exposed to a pattern of intense light $\left(27 \mathrm{~mJ} / \mathrm{cm}^{2} \mathrm{sec}\right)$ to fabricate a pattern on the target surface. Etching process was carried out in $\mathrm{NaCl}$ electrolyte with $4 \mathrm{~V}$ and $542 \mathrm{~mA}$ conditions, the chemical agent removes the uppermost layer of the substrate in the areas that are not protected by photoresist (see figure 4). Photoresist has been removed from the substrate by baking process. 
Photolithography is very precise process that if the film designed punctual and texturing process including developing and etching is correct; the results will give exact same specimen with a similar friction performance.

Figure 5 shows SEM image including a brief notations of specimen; for example the groove texture has width of $40 \mu \mathrm{m}$ and angle of $30^{\circ}$ from the reference line, perpendicular to the sliding direction. Micro-textured surfaces of SKD11 steel are shown in figure 6.

Pattern texturing is most significant process which affects great influence on friction performance. An advisory comment from MEMS specialist was taken to have an exact control on spin coating and exposure process.

\subsection{Experiment procedure}

Pin-on-disc wear test was performed with fabricated SKD11 pin on bearing steel disc each has dia. of $6 \mathrm{~mm}$ and $60 \mathrm{~mm}$ (see figure 7). Atmosphere is in-air temperature, lubricated condition with paraffin oil (saybolt no. 125/135). Tricresyl phosphate (TCP) $1 \%$ was added as anti-wear agent for lubricant, this is necessary management in order to ensure that only pure friction process can be possible by restraining the wear phenomenon. Contact pressure has 11 steps from $0.5 \mathrm{MPa}$ up to $3.5 \mathrm{MPa}$ and sliding velocity has 8 steps from $0.02 \mathrm{~m} / \mathrm{s}$ to $0.30 \mathrm{~m} / \mathrm{s}$. Contact pressure varies from lower to higher in each constant velocity during 5 min. of interval time. Each condition has 1 min. of running-in process; in general without running-in it can bring unstable friction behaviours because that surface asperity plays an important role in friction and lubrication as "break-in". Crosshatch groove textured surface of SKD11 steel before and after the friction test are shown in figure 8.

\section{RESULTS AND DISSCUSSION}

\subsection{Regime of test}

Stribeck diagram, the friction or lubrication conditions between boundary and fluid friction in three different regimes, are shown in figure 9 with Sommerfeld number, $\mathrm{S}_{\mathrm{n}}[18]$. In hydrodynamic lubrication, due to existing oil film between solids, there is no direct contact therefore coefficient of friction (COF) is low. In mixed lubrication there is an interface film, however, contact between solids often occurs. In boundary lubrication the load is totally 
supported by the asperity contact. Surface texturing can shift the Stribeck curve from one of the regimes to another and it can bring desired friction performance.

The correlations between feature and friction parameters were examined principally in elastohydrodynamic lubrication to answer the purpose. It is necessary to classify the friction data in conformity with the lubrication regimes. The plotting result in figure 10 shows that this test was performed mostly in elastohydrodynamic and mixed lubrication regimes and some in boundary lubrication regime. The lubrication mechanisms of surface texturing changes in accordance with the lubrication regime change. In boundary lubrication, the frictional coefficient was usually insensitive to speed, viscosity, or load (see also figure 11).

\subsection{Groove aspect ratio of texture}

The effects of width for friction were similar in all test conditions, as the change of contact pressure and velocity (see figure 11). Influence of angle in width $40 \mu \mathrm{m}$ on friction was wider then width $70 \mu \mathrm{m}$. In width $100 \mu \mathrm{m}$ the influence of angle was wider than $70 \mu \mathrm{m}$ but it can bring a low COF with a wise choice of angle such as $60^{\circ}$. A new parameter for groove texture has determined as aspect ratio of groove texture depth over width, similarly some researchers reported a width of dimple texture has a dependent character with a depth of texture $[3,8,17]$. In the view point of groove aspect ratio, $G_{r}$, friction behaviour of angle $40^{\circ}, 30^{\circ}$, and $20^{\circ}$ shows linearly proportional increase as the increase of $G_{r}$. Groove angle of $60^{\circ}$ and $50^{\circ}$, possibly, are not affected by $G_{r}$ besides angle of $60^{\circ}$ shows inverse proportional behaviour for $G_{r}$.

\subsection{Influence of crosshatch angle on friction}

Angle $60^{\circ}, 40^{\circ}$, and $10^{\circ}$ shows the lowest COF, at each width of $40 \mu \mathrm{m}, 60 \mu \mathrm{m}$, and 100 $\mu \mathrm{m}$ width. Similar friction behaviour was observed in most of test conditions as the contact pressure and velocity increase, except at the condition of low velocity below $0.06 \mathrm{~m} / \mathrm{s}$ which has confirmed as the regime of boundary lubrication condition. As the increase of sliding speed the friction performance gets more stabilized.

In case of width $40 \mu \mathrm{m}$, as shown in figure 12, the COF decrease inverse proportional to angle increase. Angle of pattern $60^{\circ}$ has the lowest COF, except at low sliding velocity of 
$0.02 \mathrm{~m} / \mathrm{s}$ and $0.06 \mathrm{~m} / \mathrm{s}$; it is easily assumed that at this sliding velocity of test the lubrication regimes has been shifted to mixed lubrication to boundary lubrication.

In case of width $70 \mu \mathrm{m}$, as shown in figure 13, the COF decreases and then increases. In other words, as the increase of speed the friction does not influenced much by the texture features. Angle of pattern $40^{\circ}$ shows the lowest COF in most of all texture patterns except in the regime of boundary lubrication at low velocity such as lower than $0.02 \mathrm{~m} / \mathrm{s}$. In case of low speed sliding angle of pattern $40^{\circ}$ shows lowest friction performance but as the speed increases the angle dependence on friction performance was insignificant. In case of excluding the data of angle $60^{\circ}$ and $50^{\circ}$ which confirmed as irrelevant with groove aspect ratio, the COF decrease as the angle increase.

Figure 14 shows the test results of $100 \mu \mathrm{m}$ width, the friction behaviour does not seems to have a clear dependence with the angle increase. Angle of pattern $10^{\circ}$ has the lowest COF; this additional test was carried out to verify the interdependence of angle and friction.

\subsection{Mechanism of groove texture}

Although the results show that the crosshatch groove have a strong role of improvement in friction, the discrete textures and continuous textures which considered as different mechanisms are not clearly understood,. Figure 15 shows a mechanism in the view point of lubricant flow. This theoretical analysis was performed to determine the feasibility of the lubrication mechanism suggested by experimental results. Other theoretical analyses were performed to explain the correlation of crosshatch angle and friction coefficient. Several assumptions were made to simplify the complexity of the free boundary problem associated with laminar flow, as well as incompressible Newtonian fluid; the results of the theoretical analysis are focused on to show only the trends of the effects of the groove angle and the fluid flow. Figure 15 (a) represents sliding motion of crosshatched pattern in the bird's eyes view. Lubricant flow in textured area was separately considered to determine the feasibility of groove texture mechanism. Open arrows indicate the direction of lubricant flow and closed arrow indicates the velocity of sliding motion. If the sliding direction is parallel to groove texture the velocity depends only on the width, as for example in the HagenPoiseuille law, then the flow is fully developed as shown in region $\mathrm{A}_{2}$ at grooved area. Figure 15 (b) can be expected if the tangential stresses are linearly proportional to the velocity gradients like Newtonian fluids, where difference between $h_{1}$ and $h_{2}$ shows groove depth. 
One of the reasons of difference in friction is that the total discharge $\mathrm{Q}$ is different for each texture. $\mathrm{Q}_{100 \mu \mathrm{m}}>\mathrm{Q}_{70 \mu \mathrm{m}}>\mathrm{Q}_{40 \mu \mathrm{m}}$ if velocity is constant due to $\mathrm{A}_{100 \mu \mathrm{m}}>\mathrm{A}_{70 \mu \mathrm{m}}>\mathrm{A}_{40 \mu \mathrm{m}}$, it can be rewritten as, $\mathrm{Q}_{100 \mu \mathrm{m}}=2.5 \mathrm{Q}_{40 \mu \mathrm{m}}>\mathrm{Q}_{70 \mu \mathrm{m}}=1.74 \mathrm{Q}_{40 \mu \mathrm{m}}>\mathrm{Q}_{40 \mu \mathrm{m}}$

And another reason is that fluid viscosity act as a friction component. It varies with angle of groove.

Figure 15 (b) can be expected if the tangential stresses are linearly proportional to the velocity gradients like Newtonian fluids, where difference between $h_{1}$ and $h_{2}$ shows groove depth.

If the upper specimen is moved with the velocity $u_{w}$ parallel to the lower specimen, then the velocity increases linearly in the $z$-direction, and the particles in the superjacent layers move with different velocities [19].

$$
u(y)=u_{w} \frac{y}{h}
$$

The angle of shear is

$$
\Delta \gamma \approx-\frac{u_{w} \Delta t}{h}
$$

The rate of strain is

$$
\begin{gathered}
\dot{\gamma}=\lim _{\Delta t \rightarrow 0} \frac{\Delta \gamma}{\Delta t}=-\frac{u_{w}}{h} \\
\dot{\gamma}=-\frac{d u}{d y} \\
\tau=\mu \dot{\gamma}
\end{gathered}
$$

Rate of strain will be remained as constant for all groove features.

Region B shows a branch of flow in front of grooved texture. Figure 16 (b) shows a comparison of each pressure coefficient for different angle of crosshatched groove.

If a parallel flow is superimposed on a source, the flow field about a half body is obtained [19]. 


$$
\begin{gathered}
F(z)=\left(u_{\infty}-i v_{\infty}\right) z+\frac{E}{2 \pi} \ln z+i C \\
\Phi=u_{\infty} x+v_{\infty} y \frac{E}{2 \pi} \ln r \\
\Psi=-v_{\infty} x+u_{\infty} y \frac{E}{2 \pi}\left[\theta-\arctan \left(\frac{u_{\infty}}{v_{\infty}}\right)\right]
\end{gathered}
$$

Where, $\Phi$ is velocity potential, $\Psi$ is stream function, $F(z)$ is complex stream function.

The pressure coefficient along the contour with $\theta^{\prime}=\theta_{R}=\pi-\theta$ is

$$
c_{p}=\frac{\sin \left(2 \theta^{\prime}\right)}{\theta^{\prime}}-\left(\frac{\sin \theta^{\prime}}{\theta^{\prime}}\right)^{2}
$$

For $\theta^{\prime}=0$ the pressure coefficient is $c_{p}=1$ and for $\theta^{\prime}=\pi, c_{p}=0$. Pressure coefficient decreases to $0.881,0.742,0.563,0.358$, and 0.143 , as increase of the crosshatch angle for each $\theta_{R}: 20^{\circ}, 30^{\circ}, 40^{\circ}, 50^{\circ}$, and $60^{\circ}$, respectively.

It can be rewritten as $c_{p, 20^{\circ}}>c_{p, 30^{\circ}}>c_{p, 40^{\circ}}>c_{p, 50^{\circ}}>c_{p, 60^{\circ}}$

This means that friction will be increased while entering the angle of groove influenced by above value.

Region $A_{1}$ shows the fluid flow parallel to the specimen velocity for minimum flow resistant regarding flow of fluid thickness $h_{2}$. The sliding length moving on the groove parallel to the sliding direction has similarity as shown in figure 17. In this study, it was already confirmed that COF is function of width and angle, so the groove sliding length " $G$ " can be calculated by following equation. $G_{l}$ of black rounded rectangular area shown in figure 16, which shows low friction performance according to the fluid flow length, has similar value; it can be assumed that COF is function of the parameter $G_{l}$.

$$
\begin{gathered}
\mu \propto f\left(\theta_{R}, w\right) \\
G_{l}=\frac{w}{\cos \theta_{R}} \\
\mu \propto f\left(G_{l}\right)
\end{gathered}
$$

Finally, in statistical approach the polynomial fit of data can be obtained like figure 18 . Although the friction and wear are not a unique material property but a system response, yet it has the tendency to represent tribological properties. It can be said that the influence 
of angle and width on friction in micro-grooved crosshatch texture under lubricated sliding exist and the coefficient of friction depends on the parameter $G_{l}$.

\section{CONCLUSION}

Tribological studies on micro-grooved crosshatch pattern fabricated by photolithography on the SKD11 steel specimens for examining the correlation of crosshatch angle and groove width under mixed and elastohydrodynamic lubrication showed that:

- Friction reduction can be achieved by crosshatched micro-groove texturing,

- Crosshatch angle of groove texture seems to be an important parameter to design surface texture as well as groove aspect ratio,

- Friction decrease according to decrease of the groove aspect ratio and increase of the groove sliding length,

- Marking $G_{l}=1.0$ as a turning point, friction increase below this level and decrease above.

- The possibility of pressure increase mechanism at branch in front of crosshatched groove has been modelled by limited theoretical analysis.

\section{ACKNOWLEDGMENTS}

The author would like to thank the Ministry of Education, Culture, Sports, Science and Technology (MEXT) of Japan for a MEXT scholarship, and also thank the Ministry of Commerce, Industry and Energy (MOCIE) and Korea Industrial Technology Foundation (KOTEF) through the Human Resource Training Project for Regional Innovation for financial support of partial experiment.

\section{REFERENCES}


[1] Wang, X., Kato, K., Adachi, K., Aizawa, K.: Loads carrying capacity map for the surface texture design of SiC thrust bearing sliding in water. Tribol. Int. 36(3), 189197 (2003)

[2] Wakuda, M., Yamauchi, Y., Kanzaki, S., Yasuda, Y.: Effect of surface texturing on friction reduction between ceramic and steel materials under lubricated sliding contact. Wear 254, 356-363 (2003)

[3] Kovalchenko, A., Ajayi, O., Erdemir, A., Fenske, G., Etsion, I.: The effect of laser texturing of steel surfaces and speed-load parameters on the transition of lubrication regime from boundary to hydrodynamic. Tribol. Trans. 47, 299-307 (2004)

[4] Siripuram, R.B., Stephens, L.S.: Effect of deterministic asperity geometry on hydrodynamic lubrication. ASME J. Tribol. 126(3), 527-534 (2004)

[5] Costa, H.L., Hutchings, I.M.: Hydrodynamic lubrication of textured steel surfaces under reciprocating sliding conditions. Tribol. Int. 40, 1227-1238 (2007)

[6] Lu, X., Khonsri, M.M.: An experimental investigation of dimple effect on the stribeck curve of journal bearings. Tribol. Lett. 27, 169-176 (2007)

[7] Etsion, I., Burstein, L.: Improving tribological performance of piston rings by partial surface texturing. Tribol. Trans. 39(3), 677-683 (1996)

[8] Etsion, I., Kligerman, Y., Halperin, G.: Analytical and experimental investigation of laser-textured mechanical seal faces. Tribol. Trans., 42(3), 511-516 (1999)

[9] Wang, Q.J., Zhu, D.: Virtual texturing: modeling the performance of lubricated contacts of engineered surfaces. J. Tribol. 127(4), 722-728 (2005)

[10] Xiaobin Lu, Khonsari M. M.: An Experimental Investigation of Dimple Effect on the Stribeck Curve of Journal Bearings Tribol Lett 27, 169-176 (2007)

[11] Etsion I, Kligerman Y, Halperin G.: Analytical and experimental investigation of lasertextured mechanical seal faces. STLE Tribology Transactions 42, 511-516 (1999)

[12] Wang X, Kato K, Adachi K, Aizawa K.: The effect of laser texturing of SiC surface on the critical load for the transition of water lubrication mode from hydrodynamic to mixed. Tribology Int. 34, 703-711 (2001)

[13] Burstein L, Ingman D.: Pore ensemble statistics in application to lubrication under reciprocating motion. Tribol. Trans. 43, 205-212 (2002)

[14] Ryk G, Kligerman Y, Etsion I.: Experimental investigation of laser texturing for reciprocating automotive engines. Tribol Trans 45, 444-449 (2002)

[15] Pettersson U, Jacobson S.: Influence of surface texture on boundary lubricated sliding contacts, Tribology Int. 36, 857-864 (2003)

[16] Wang X, Kato K, Adachi K, Aizawa K.: Loads carrying capacity map for the surface texture design of SiC thrust bearing sliding in water. Tribology Int. 36, 189-197 (2003)

[17] Brizmer V, Kligerman Y, Etsion I.: A laser surface textured parallel thrust bearing. STLE Tribology Trans. 46, 397-403 (2003) 
[18] Czichos H., Habig K.-H., Tribologie Handbuch, Vieweg, Wiesbaden (1992)

[19] Krause E.: Fluid Mechanics, Springer Berlin Heidelberg, New York (2005) 

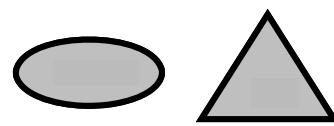

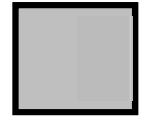

(a)
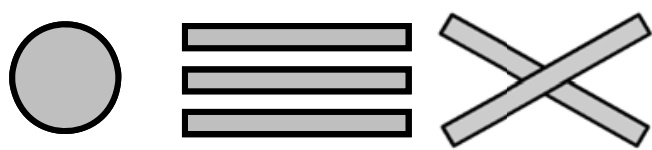

(b)

Figure 1: Shape of features and classification of surface textures

(a) Discrete textures, and (b) Continuous textures.

(a)

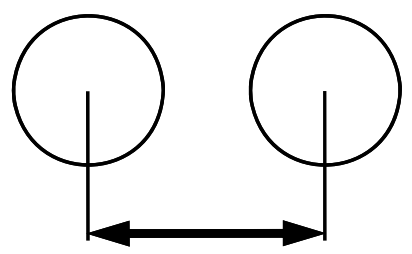

Pitch

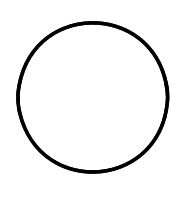

Size<smiles>c1ccccc1</smiles><smiles>c1ccccc1</smiles><smiles>c1ccccc1</smiles><smiles>c1ccccc1</smiles>

Array

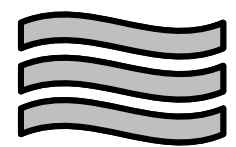

$\square$ 


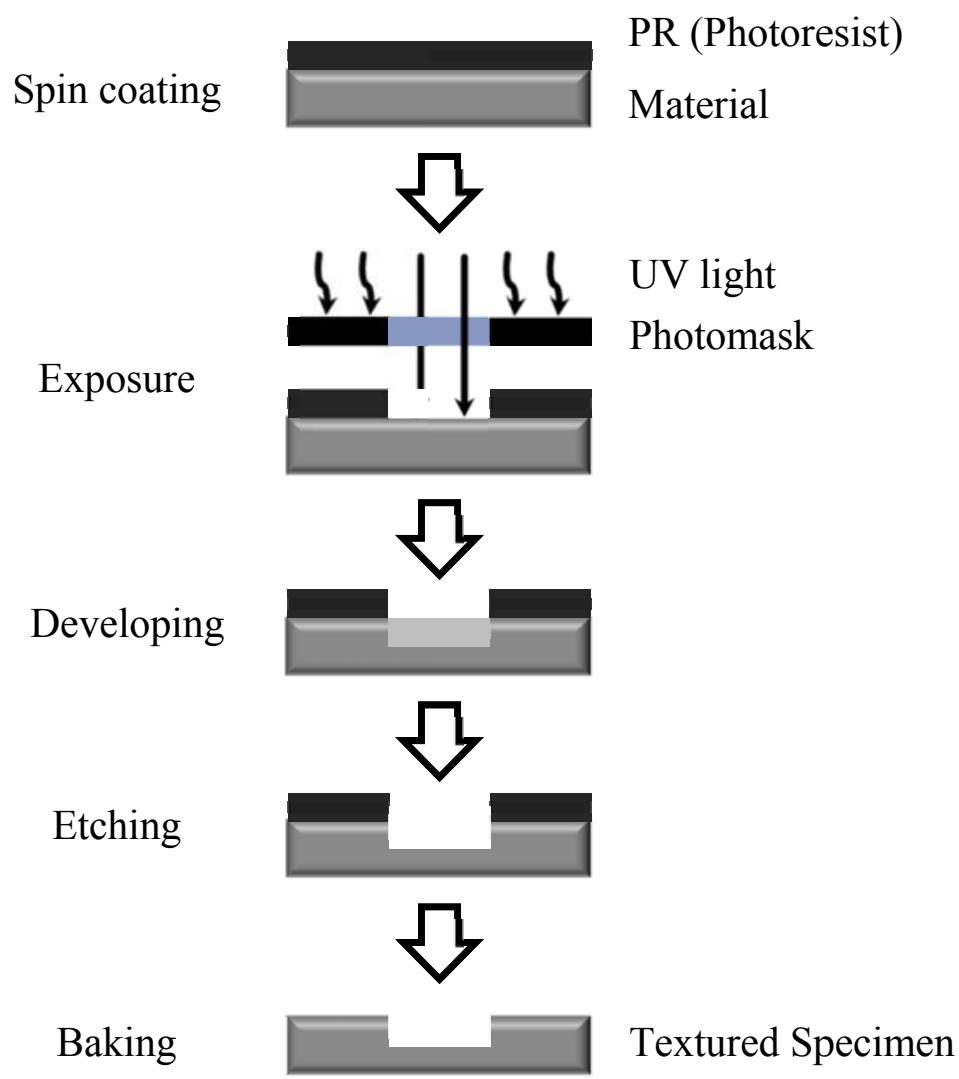

Figure 3: Photolithography process to fabricate a surface texture.

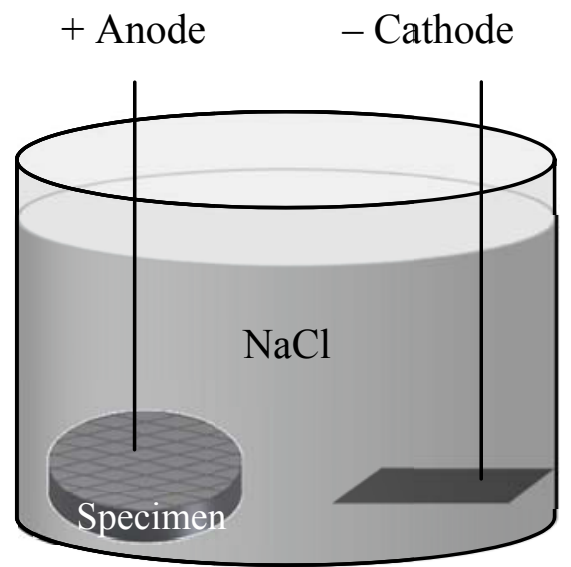

Figure 4: Schematic of etching process. 


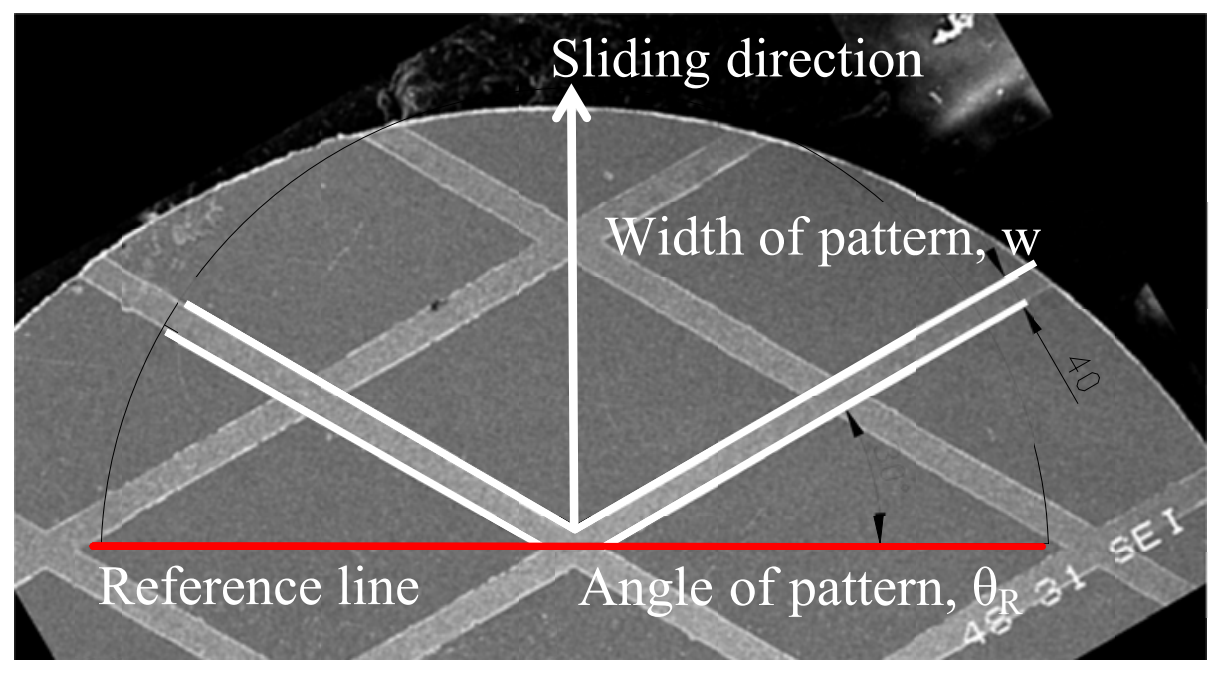

Figure 5: Notation of surface textured specimen.

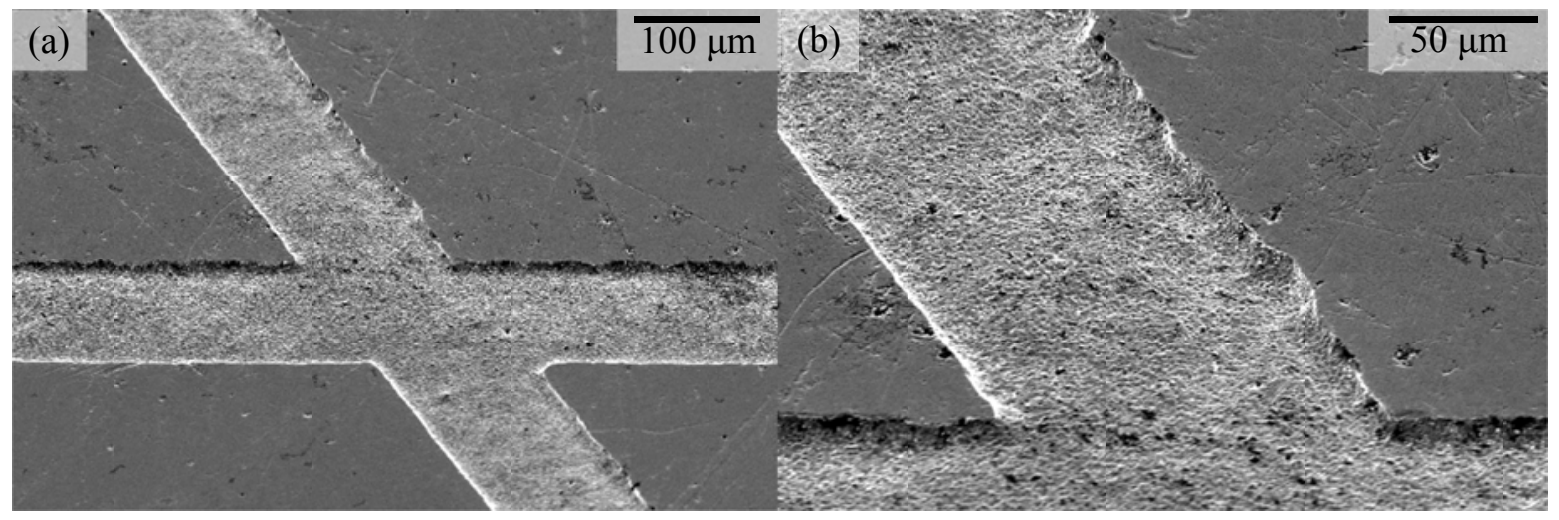

Figure 6: SE micrographs of the textured surface of the SKD11 steel (a) micro-grooved crosshatch with angle $30^{\circ}$ and width $100 \mu \mathrm{m}$, and (b) with high magnification.

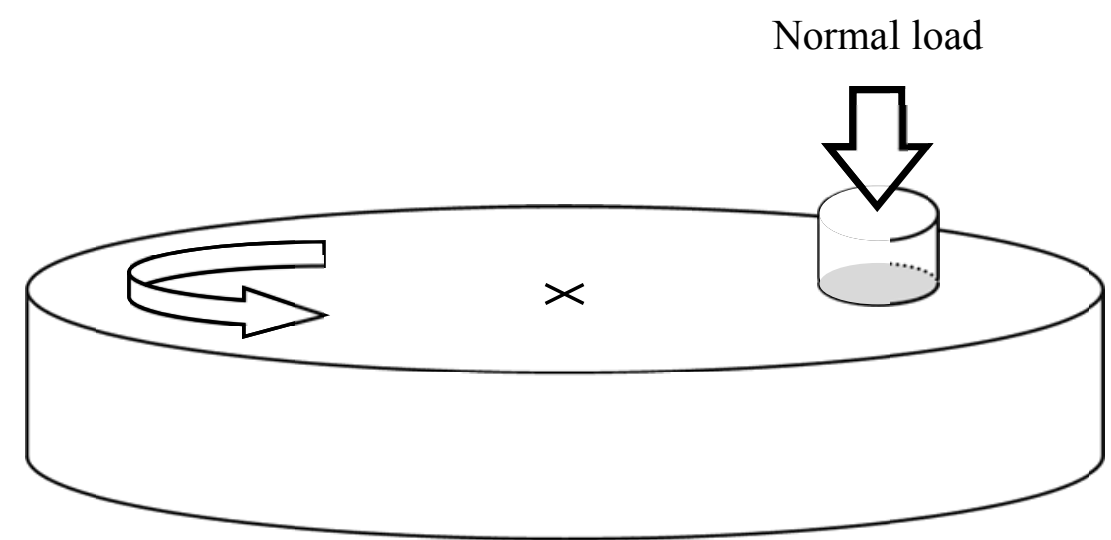

Figure 7: Schematic diagram of pin-on-disc friction test. 


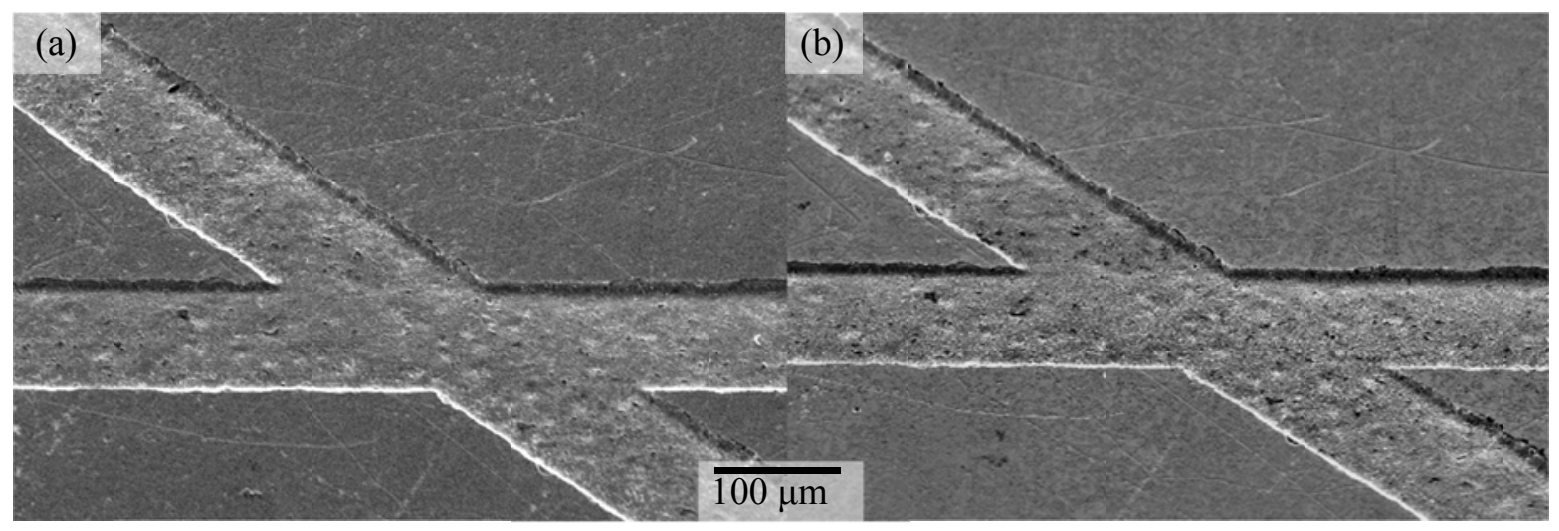

Figure 8: SE micrographs of the textured surface (a) before, and (b) after the tribological test.

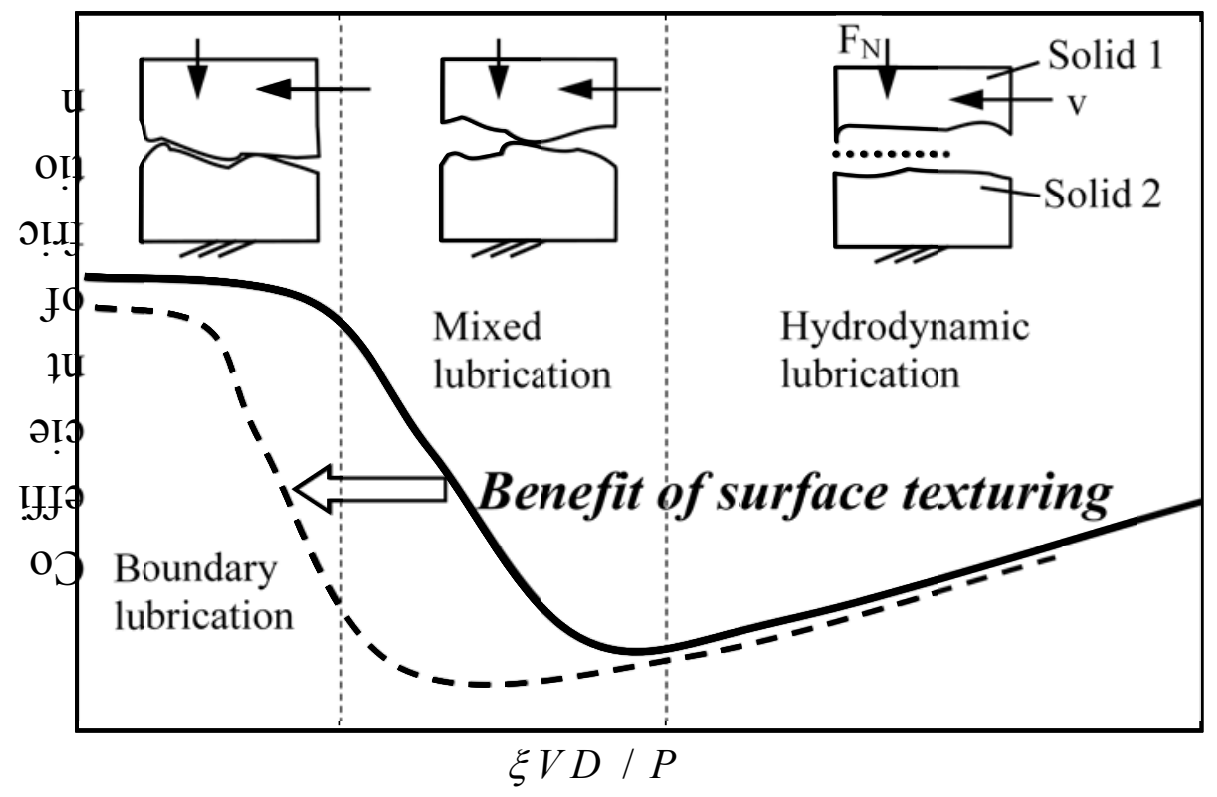

Figure 9: Effect of surface texturing and Stribeck curve. 

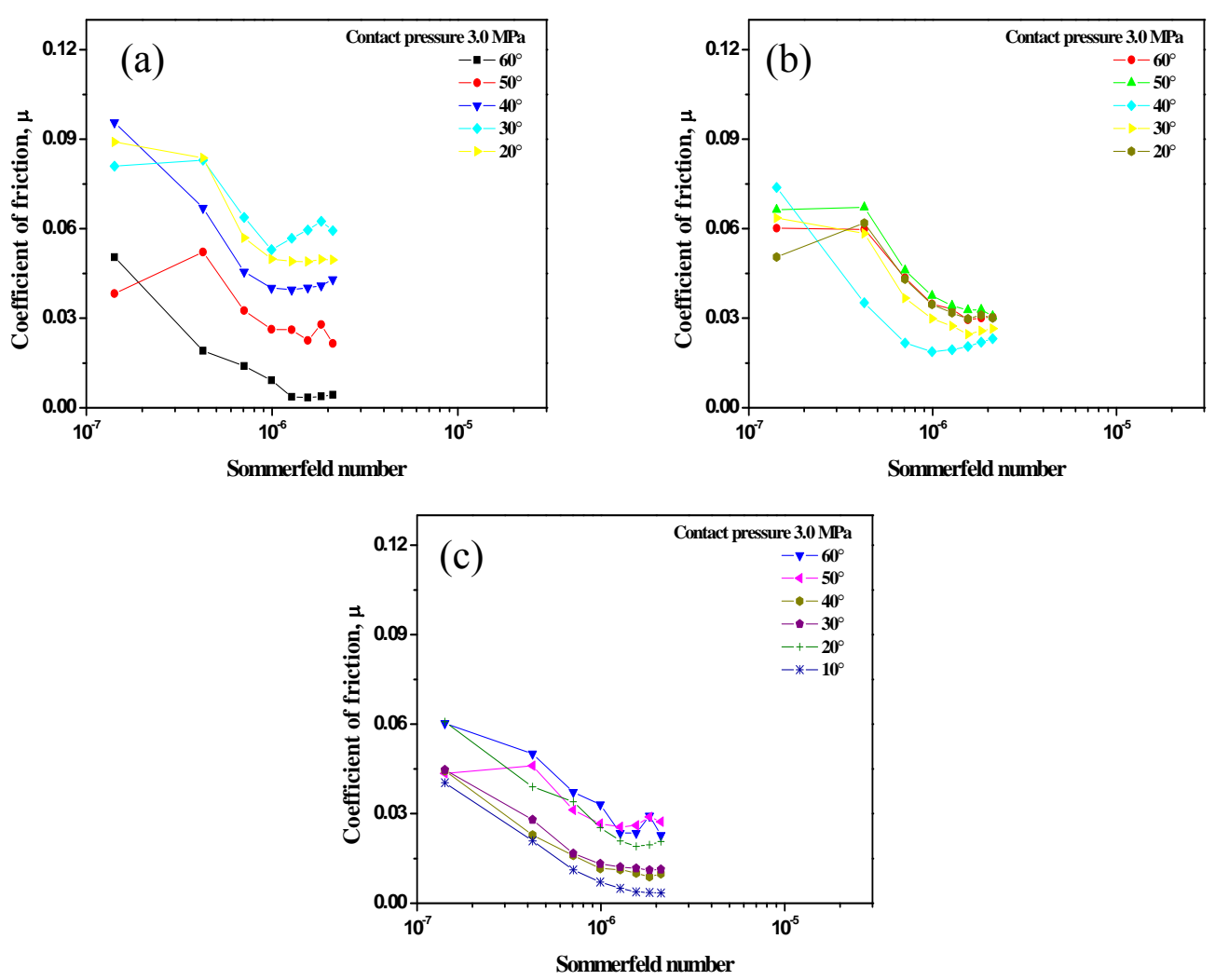

Figure 10: Sommerfeld number for coefficient of friction to verify the region of test at contact pressure $3.0 \mathrm{MPa}$ with width (a) $40 \mu \mathrm{m}$, (b) $70 \mu \mathrm{m}$, and (c) $100 \mu \mathrm{m}$. 
(a)

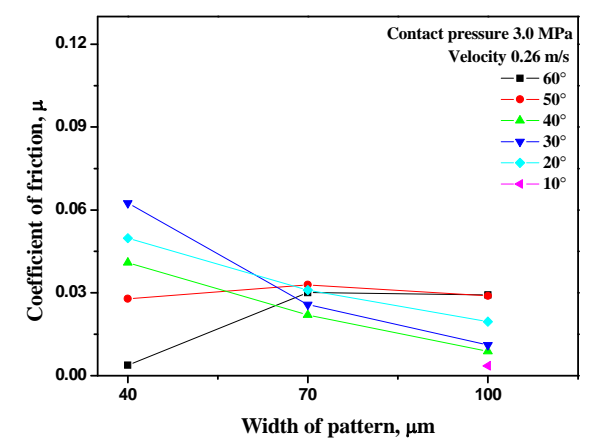

(b)

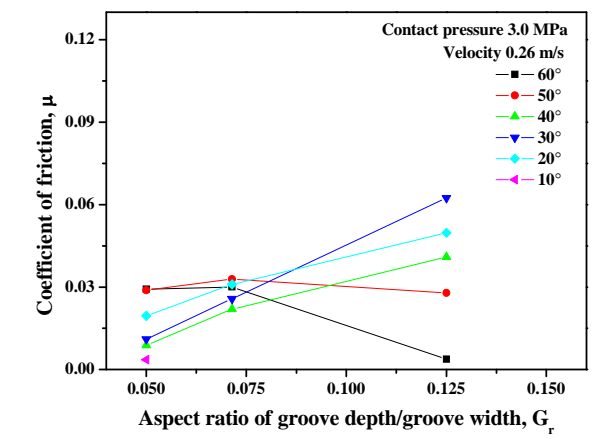

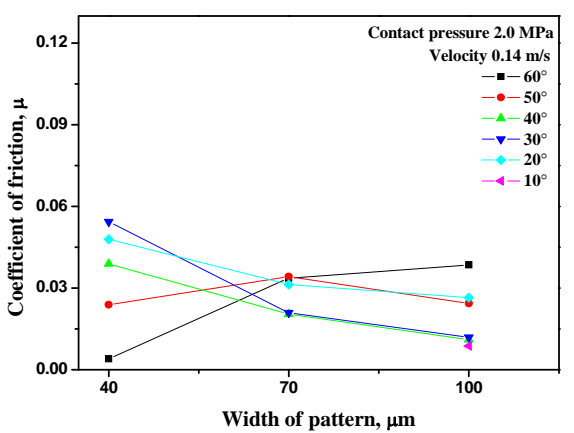

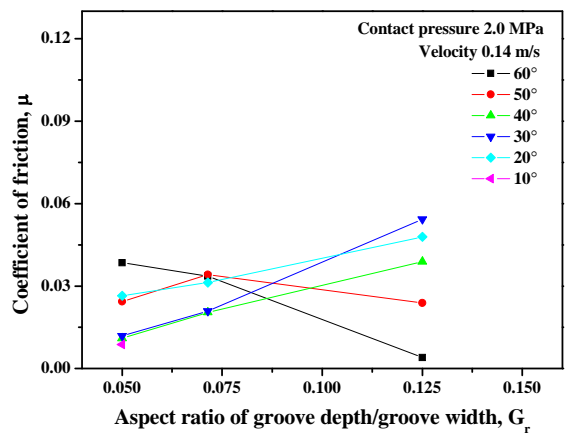

Figure 11: Coefficient of friction versus (a) width of groove, and (b) groove aspect ratio. 

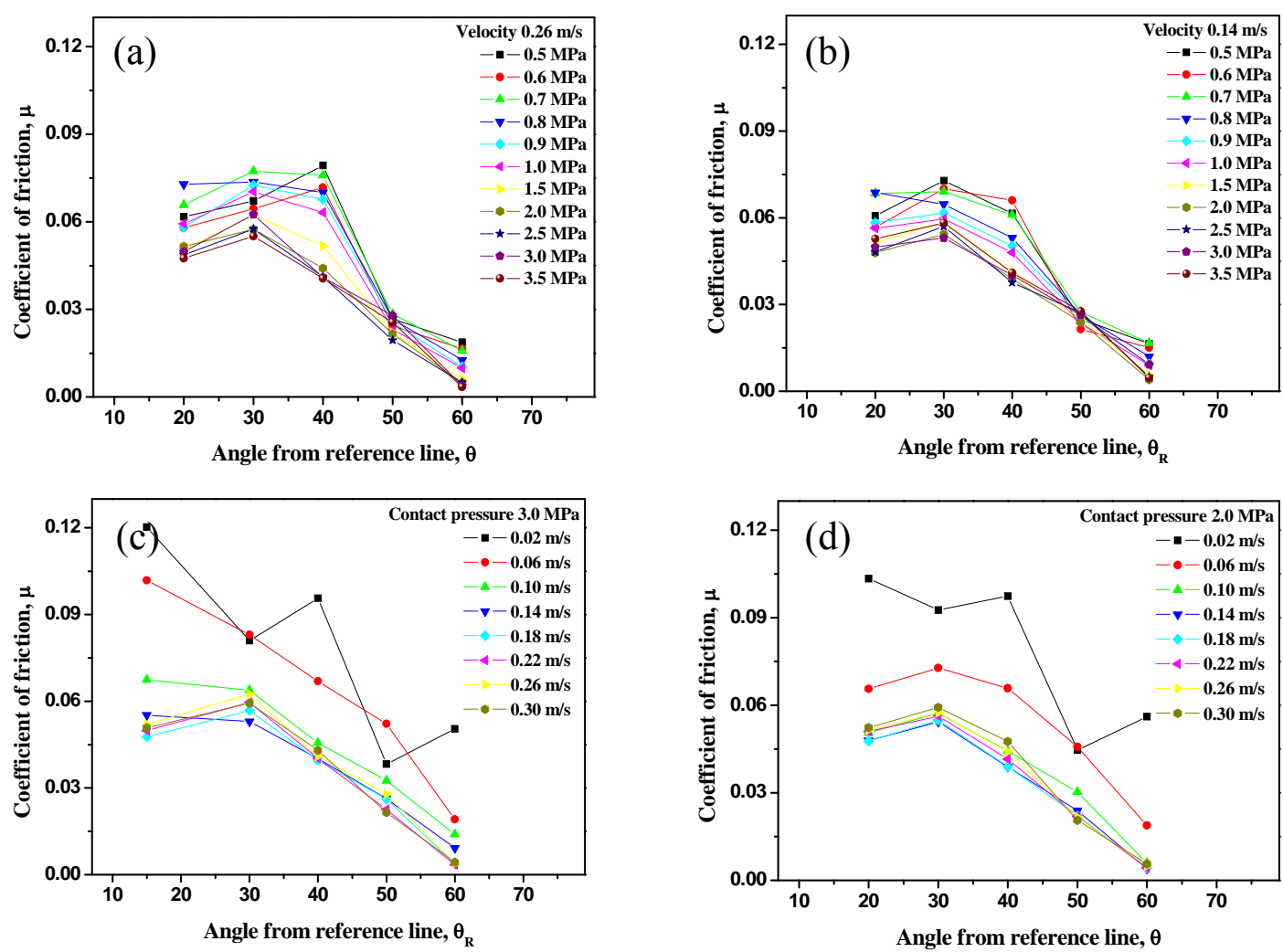

Figure 12: Friction coefficient versus angle of pattern for width $40 \mu \mathrm{m}$, at sliding velocity of (a) $0.26 \mathrm{~m} / \mathrm{s}$, (b) $0.14 \mathrm{~m} / \mathrm{s}$. at contact pressure of (c) $3.0 \mathrm{MPa}$, (d) $2.0 \mathrm{MPa}$. 

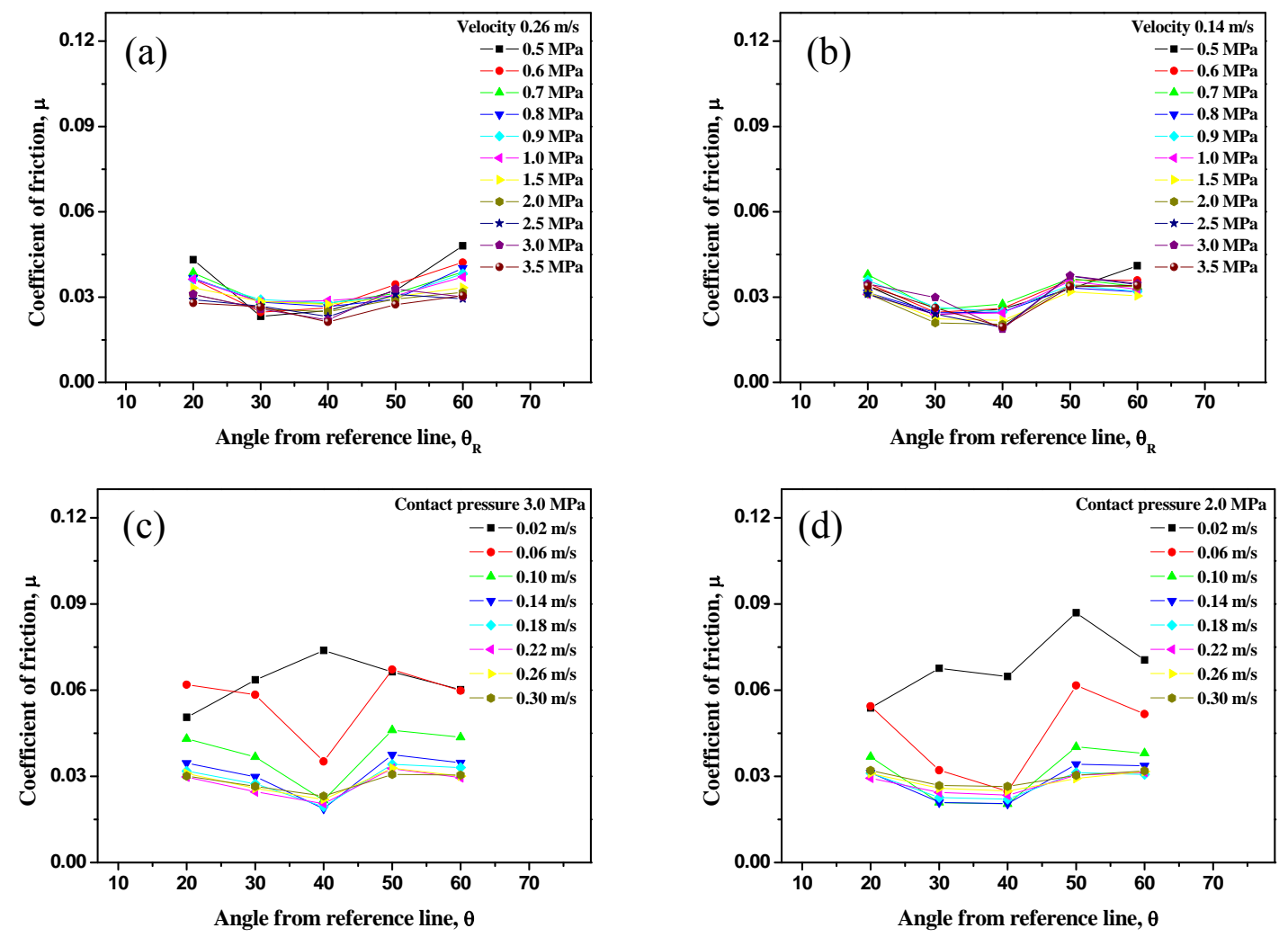

Figure 13: Friction coefficient versus angle of pattern in width $70 \mu \mathrm{m}$, at sliding velocity of (a) $0.26 \mathrm{~m} / \mathrm{s}$, (b) $0.14 \mathrm{~m} / \mathrm{s}$. at contact pressure of (c) $3.0 \mathrm{MPa}$, (d) $2.0 \mathrm{MPa}$. 

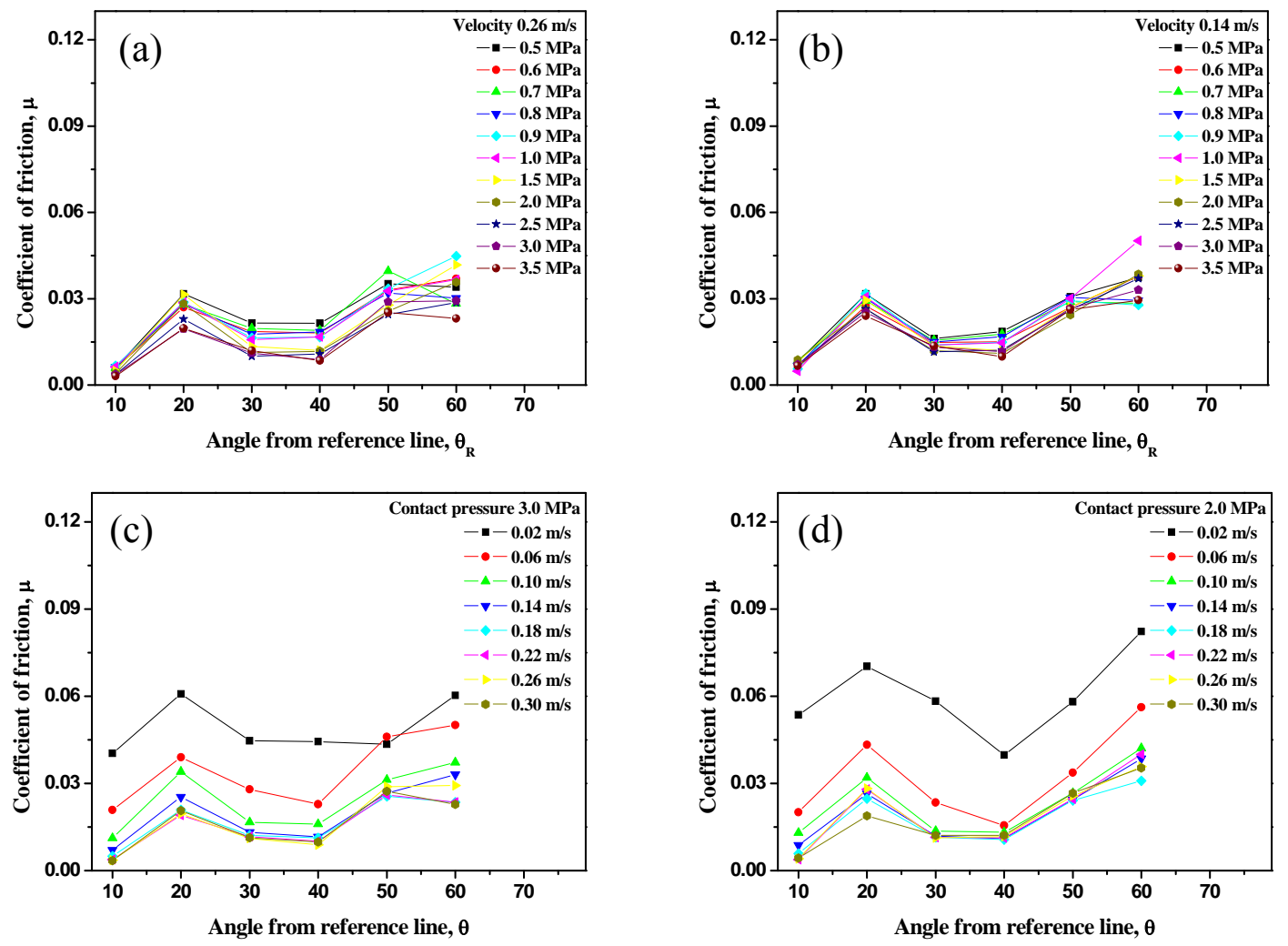

Figure 14: Friction coefficient versus angle of pattern in width $100 \mu \mathrm{m}$, at sliding velocity of (a) $0.26 \mathrm{~m} / \mathrm{s}$, (b) $0.14 \mathrm{~m} / \mathrm{s}$. at contact pressure of (c) $3.0 \mathrm{MPa}$, (d) $2.0 \mathrm{MPa}$. 


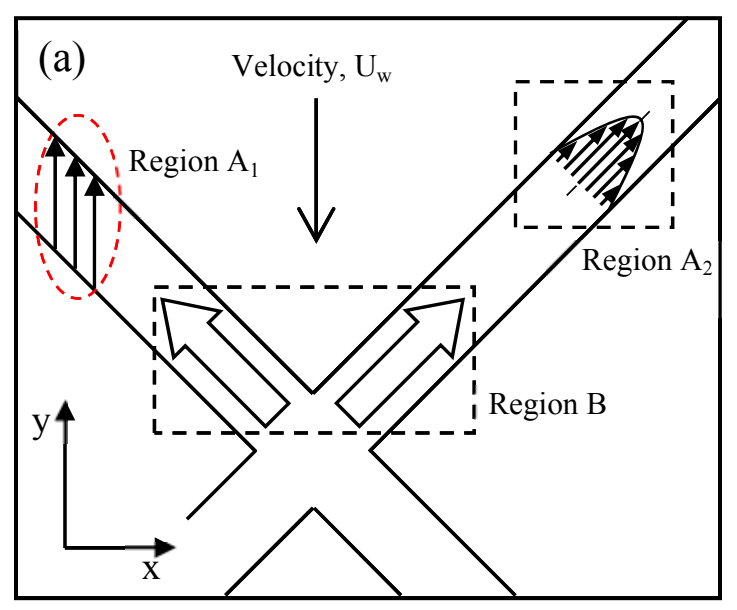

(b)
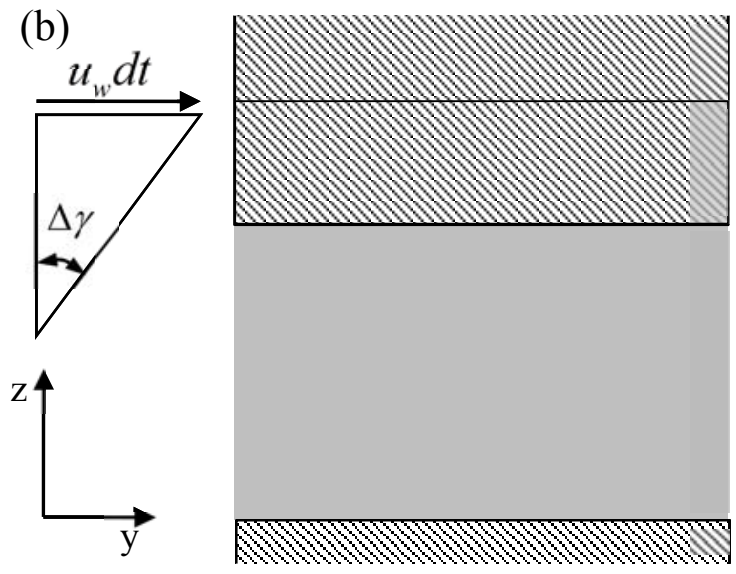

Figure 15: Schematic mechanisms of crosshatched groove texture in the view of fluid flow (a) bird's eye view, (b) cross section view. 


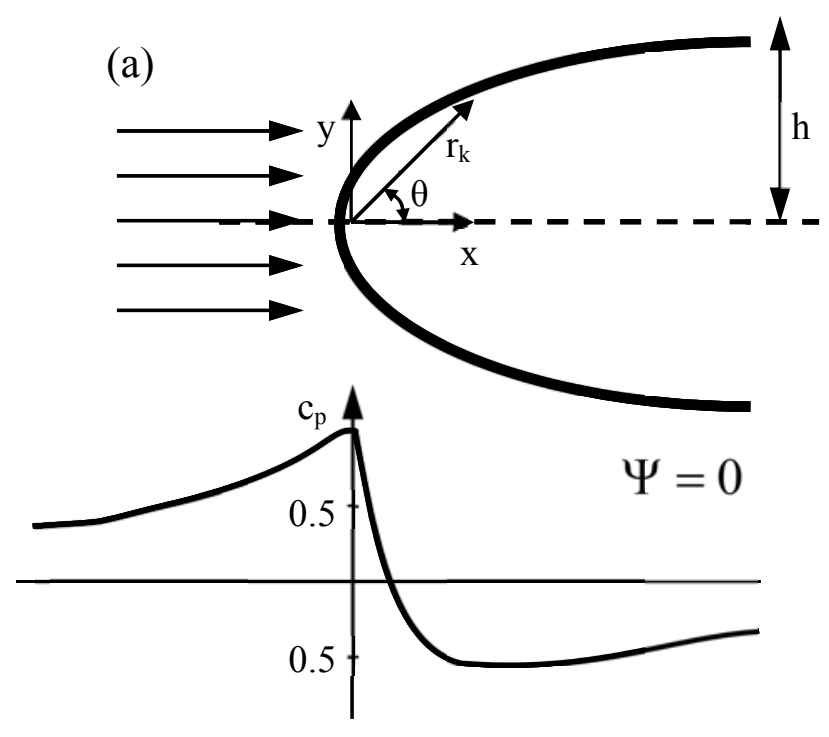

(b)
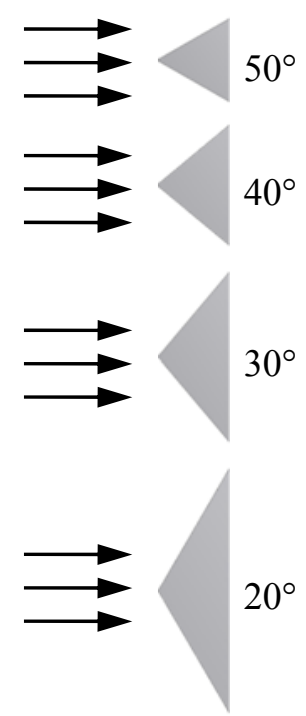

Figure 16: Schematic mechanisms of crosshatched groove texture

(a) pressure coefficient along contour,

(b) comparison of $c_{p}$ for each crosshatched groove angle

$$
c_{p}: 50^{\circ}<40^{\circ}<30^{\circ}<20^{\circ}
$$




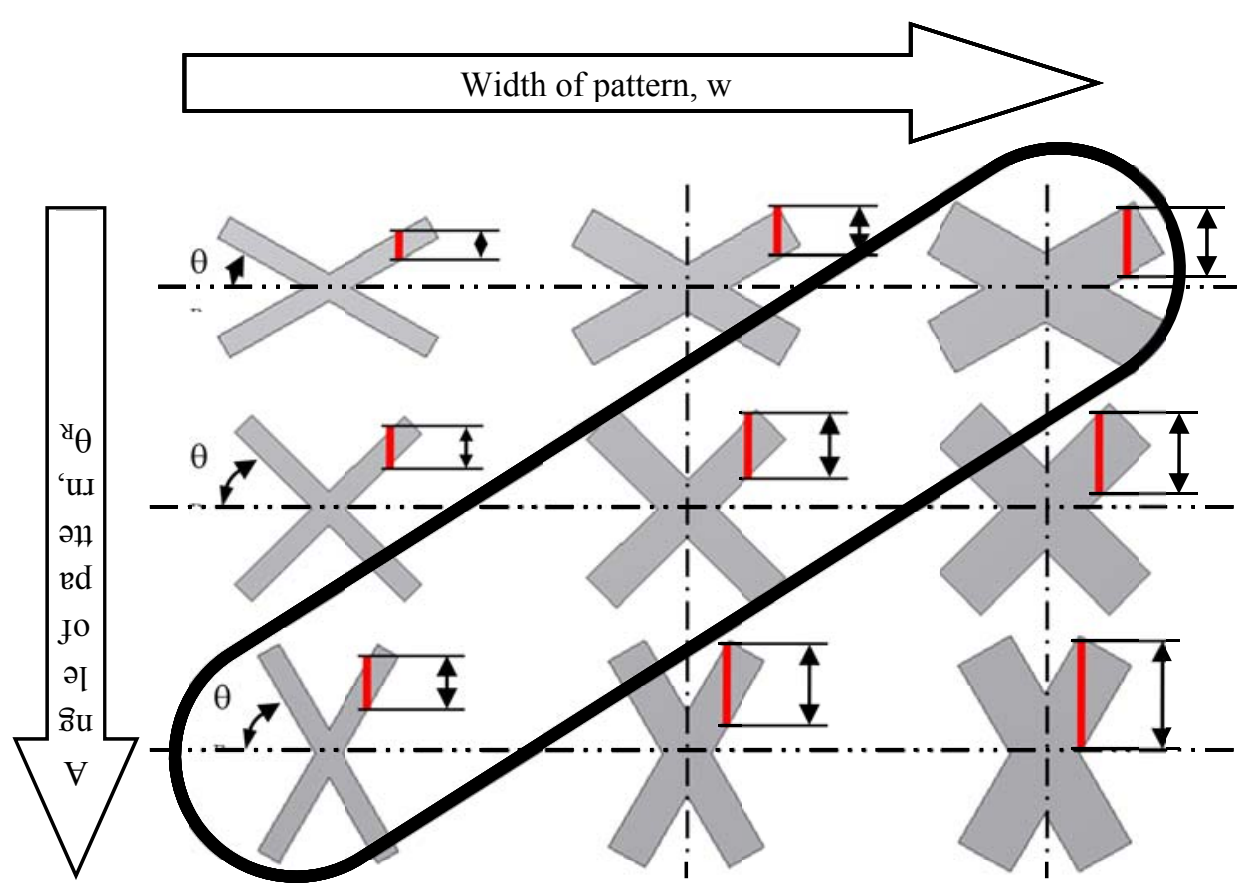

Figure 17: Schematic comparison of groove sliding length as variable of angle and width.
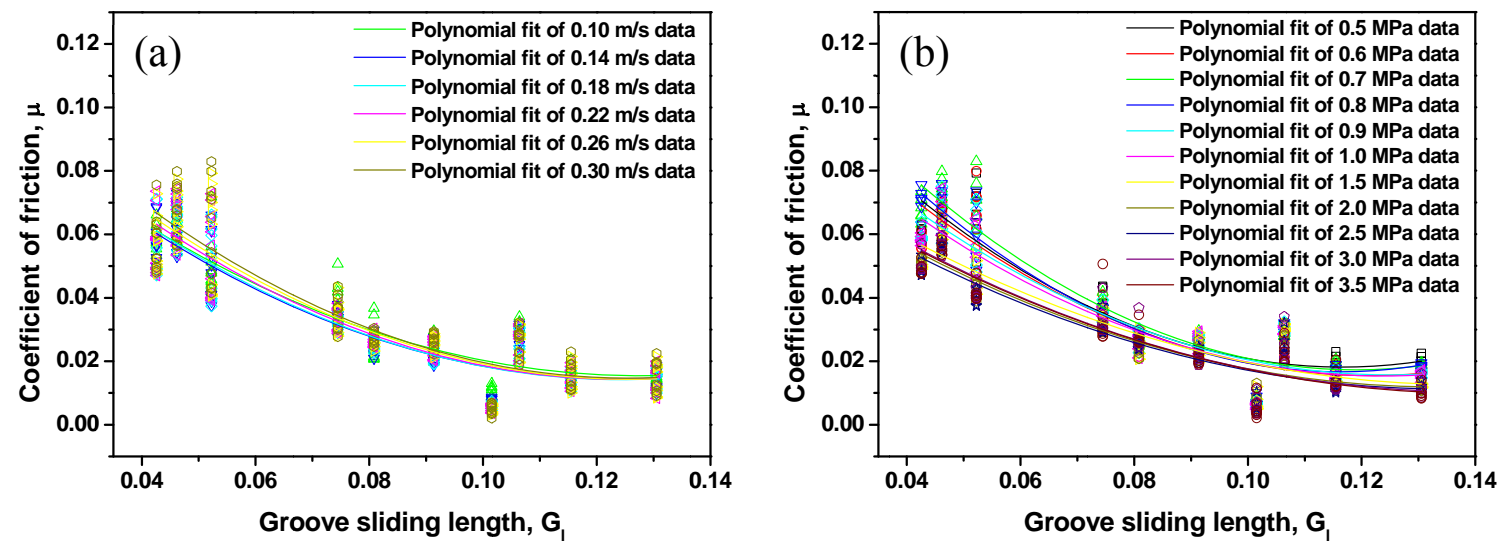

Figure 18: Polynomial fit of friction coefficient versus groove sliding length, $G_{l}$ (a) as a function of velocity, and (b) as a function of pressure. 